Basic problems of harmonizing

Tax Law in the European communities

Gerhard Laule 121

A responsabilidade do transportador aéreo pelo fato do serviço e o Código de Defesa do Consumidor

Cláudia Lima Marques 133

Algumas considerações sobre os sistemas tributários dos estados federativos em desenvolvimento

Rômulo Maya 159

\section{A conversão da dívida}

externa latino-americana em projetos ambientais: uma resposta da "novissima ordem econômica internacional" aos problemas do endividamento e do

meio ambiente

Isabela Soares Micali e Maristela Basso

O juiz e o princípio do contraditório - Carlos Alberto Alvaro de Oliveira 178

Instrumental alternativo:

pequena contribuição

Rui Portanova 185

A noção de sistema no direito privado: unidade ou pluralidade Carlos Eduardo López Rodríguez 20

O pedido

Cesar Viterbo Matos Santolim 222

Responsabilidade pela sucumbência no Código de Processo Civil

Ovídio A. Baptista da Silva 227

A teoria das nulidades no Direito

português e brasileiro

Sandra Della Pola da Silva 234

Eficácia social da prestação jurisdiciona Teori Albino Zavascki 248

\title{
Apresentando a nossa Casa
}

Memória institucional

Ely Souto dos Santos

Professor Titular, mestre em Antropologia Filosófica,

Doutor em Ciências Sociais, Livre Docente em Filosofia Social

Doutor em Direito, Livre Docente em Direito do Trabalho.

Perder a memória, esquecer, até certo ponto, é uma necessidade para as pessoas físicas. E a disponibilidade mental para aprender novas coisas, apagar más recordações, amenizar sofrimentos, predispor-se a novos empreendimentos.

Perder a memória para os agrupamentos humanos, para as instituições é a morte, a perda de identidade, a perda dos horizontes, o apagamento de suas finalidades.

Nenhuma aventura humana persiste sem um ponto de partida e sem um horizonte proposto, de maneira consciente ou inconsciente. Para tudo há um ponto alfa e um ponto ômega, que permite traçar um roteiro ou acenar com uma esperança.

Nossa Faculdade de Direito não foi diferente. Daqui a sete anos completa-se o segundo milênio do cristianismo. Ao nascer, muito embora sob o signo do positivismo, sob os alicerces de nossa casa, herdamos mil e novecentos anos de cultura ocidental. E, neste final de século, já estamos colaborando com quase cem anos de cultura jurídica.

Fizemos muito ou fizemos pouco? Ou, apenas cumprimos com nosso dever? No dizer de Ortega y Gasset, o homem não é ele, tão somente, é ele e sua circunstância; é ele e tudo o que está ao seu redor. Acaba sendo causa e efeito de mudanças. E já não se fala mais em causa única e sim em concausas. Porque, no dizer de Augusto Comte, os vivos são sempre e cada vez mais governados pelos mortos. Ou seja, já nascemos com história e fazendo história.
O que fazemos são atos nossos. Mas o julgamento destes atos são atos de outros, nossos pósteros. A repetição, a interpretacão ou a reinterpretação dos atos passados, de maneira incessante, por muitas e muitas vezes, por muitas e muitas pessoas, por muitas e muitàs gerações mantêm presente tudo quanto já foi feito, como se estivessem acontecendo quase agora, fazendo com que pessoas se identifiquem com as instituições e façam de ambas uma única história, de maneira que as vidas das pessoas não possam ser narradas sem a das instituições que serviram e que a vida das instituições não possa ser entendida senão através daquelas vidas humanas que a elas se dedicaram. Ou seja, a história da humanidade, pode-se dizer sem exagero, nada mais que o encadeamento de atos dos homens praticados através de suas instituições.

E quase impossível falar de nossa Faculdade de Direito sem lembrar de Manoel André da Rocha ${ }^{1}$, e vice-versa. Da mesma maneira, não se pode falar em mestrado sem lembrar de Clóvis Veríssimo do Couto e Silva ${ }^{2}$.

As informações que seguem foram colhidas pelo autor, principalmente, em uma monografia de lavra do nosso colega, já agora aposentado, João Pedró dos Santos3 vencedora do Concurso de Monografias, comemorativo dos 75 anos da Faculdade, em três volumes, 666 páginas, mimeografada, intitulada $A$ Faculdade de Direito de Porto Alegre, subsídio para a sua história existente em nossa Faculdade, que vai ser atualiza-

R. Fac. Direito UFRGS, Porto Alegre, 9(1): 7-15, nov. 1993 
da, pois data de 1975. A apresentação é sucinta como sói acontecer em um artigo de revista.

\section{0 - Nascimento da faculdade}

Ao contrário do que todos pensam, a faculdade não nasceu na Av. João Pessoa e nem seu primeiro diretor foi Manoel André da Rocha. Não foi pública e nem gratuita.

A Faculdade de Direito, como não poderia deixar de ser, nasceu sob a égide do Poder Judiciário, que era provido com bacharéis oriundos de outros estados ou formados pelas Faculdades de Direito do Recife ou de São Paulo.

Tudo aconteceu por iniciativa do Des. James Franco, presidente do Superior Tribunal de Justiça do Estado, desde 1894, juntamente com o Des. Thompson Flores e apoio de outro desembargador, Antonio Augusto Borges de Medeiros, então na presidência do Estado.

A inspiração positivista teve a mão de Julio de Castilhos, que prega a criação dos estabelecimentos de ensino livres "independentes da vexatória tutela oficial, fora da estufa de subvenções orçamentárias que, além de ilegítimas, são humilhantes". O ensino livre, ideal republicano, positivista, não teve o mesmo entusiasmo em outros estados-membros da Federação. Em 10 de fevereiro de 1900, acorreram as mais importantes personalidades, para ouvir a declaração de Thompson Flores, em sala do Atheneu Riograndense, de que estava fundada a Faculdade Livre de Direito.

O Des. Carlos Thompson Flores é o primeiro diretor da casa. Merece referência a reunião de 19 de fevereiro do mesmo ano, quando foram aprovados os estatutos e apresentada a relação dos primeiros professores. catedráticos e substitutos. Nesta mesma sessão, o Dr. Antonio Fausto Neves de Souza assumiu o compromisso de contribuir com $2 \%$ dos seus vencimentos, para constituir o patrimônio da instituição, que se criava longe dos favores dos cofres oficiais.

Os estatutos tomaram por base aqueles da Faculdade Livre de Ciências Jurídicas e Sociais do Rio de Janeiro, observando a organização didático-administrativa das faculdades oficiais, em atendimento à legisl ção federal. A 24 de fevereiro de 1900, instalou-se a Congregação.

\section{0 - Faculdade livre}

$O$ decreto $\mathrm{n}^{\mathrm{0}} 1.134$, de 30 de março de 1853 , permitiu a criação das faculdades, para abranger os Cursos de Direito, passando a junta composta de todos os professores a chamar-se de Congregação de Lentes.

Pelo Decreto $\mathrm{n}^{\mathrm{0}}$ 7.247, de 19.04.1879, o Poder Público permitia, a associação de particulares para a fundação de cursos onde se ensinassem as matérias constantes de qualquer curso superior, sendo-lhes outorgada a qualidade de Faculdades Livres, com autorização para conferir graus acadêmicos. Isto porque, segundo o Ministro Carlos Leôncio de Carvalho, "o Estado não é infalível, nem pode arrogar-se o monopólio do saber".

A reforma de Benjamin Constant, em 1881, autoriza o Governo, ouvido o Conselho de Instrução Superior, a conceder a instituição particular o título de Faculdade Livre, com todos os privilégios e garantias das Faculdades Federais, dando-lhes o direito de conferirem aos alunos os mesmos graus acadêmicos, na conformidade da legislação reguladora das faculdades federais.

A Lei $n^{\circ} 314$, de 30.10.1885, versando sobre o ensino de Direito, contempla em um só curso a denominação de Ciências Jurídicas e Sociais, em cinco anos.

Era exigido das Faculdades Livres um patrimônio mínimo de 50:000\$000 (cinqüenta contos de réis) e a freqüência mínima de 30 alunos em dois anos de funcionamento. A nossa Faculdade de Direito nasceu livre dentro de tais exigências.

3.0 - Instalação solene da faculdade

Ocorreu às 15 horas do dia 03 de maio de 1900, coincidindo com os festejos do 400 anos de descobrimento do Brasil. Era uma quinta-feira, feriado nacional. $O$ erro de datação do dia da descoberta do Brasil, à época, ainda não havia sido corrigido. a sabe que a descoberta ocorreu em nidade. Assim, nascia livre a primeira Facul- dade de Direito do Estado do Rio Grande do Sul, a sétima do país, no dizer de João Pedro dos Santos "descomprometida com filhos de barões nem mestres conselheiros, sem aristocratização do ensino e nem aulas do estilo coimbrão (...) com homens livres, tendo por meta o amor à liberdade (...) e por meio as instituições republicanas".

\section{0 - Corpo discente}

4.1 - Os primeiros alunos

Eles se matricularam dois dias antes da instalação solene da Faculdade, ad cautelam. Eram doze (apóstolos?), tendo Anápio Jobim como primeiro aluno matriculado.

4.2 - Colaboração dos alunos

Em duas ocasiões os primeiros estudantes marcaram sua presença de maneira decisiva aos destinos da Faculdade. A primeira, quando da construção da sede, angariando fundos através de promoções sociais, como se verá mais abaixo. A segunda, quando do desentendimentos da Faculdade com o Governo central. Com efeito:

a) Em 05.04.1911, o santanense Rivadávia Correa foi guindado ao Ministério do Interior, no governo do Mal. Hermes da Fonseca. Com ele veio a chamada reforma Rivadávia, de inspiração positivista, abolindo toda e qualquer fiscalização do ensino, onde o magister dixit, cedia o lugar ao discipulus dixit porque "pouco importa a mátéria que um homem superior ensinar aos jovens. O essencial é que o homem seja superior". Ou melhor, estabelecia a mais ampla liberdade de cátedra. Não durou muito.

b) Em 1914 o Presidente Wenceslau Brás leva para o Ministério do Interior o santamariense Carlos Maximiliano, que não era ๑ositivista, e restabeleceu através do Decreto $\mathrm{n}^{\mathrm{O}} 11.530$, de 18 de março de 1915 , a fiscalização, que desagradou aos positivistas gaúchos liderados por Borges de Medeiros.

c) A reação da Faculdade foi de não acatamento das determinações federais. $E$ conseqüência foi o não reconhecimento dos diplomas fornecidos pela Faculdade fora do território rio-grandense. O Supremo Tribunal Federal confirmou as negativas de reco- nhecimento e registro dos diplomas expedidos pela nossa Faculdade.

d) Esta exclusão de atuação dos diplomados gaúchos fora do Estado tornou-se embaraçosa ante o silêncio da administração da Faculdade. Em 1917, os alunos fundam o seu Centro Acadêmico e reivindicam, de forma pacífica mas veemente, que a Faculdade se dobre às exigências federais, modificando seus estatutos de molde a submeter-se à fiscalização da lei educacional vigente.

e) O então diretor, André da Rocha, entendeu seria melhor aguardar que a reforma de Carlos Maximiliano passasse sob o crivo do Congresso Nacional, pois havia a possibilidade de rejeição pelo Parlamento.

Ante as reticências do Sr. Diretor, os alunos apelaram diretamente aos professores, no que foram apoiados, com a imediata convocação da Congregação. Esta decidiu pelo pedido de reconhecimento. Os estatutos foram revisados, reorganizou-se o corpo docente, foi introduzido o exame vestibular, excluíram-se os alunos ouvintes. Em 2 de março de 1919, a Faculdade obteve sua equiparação, sendo nomeado o Des. Manoel Orphelino Tostes Inspetor Federal junto à Faculdade, situação que perdurou até a incorporação da Faculdade à Universidade Federal.

\section{3 - Os alunos atuais}

Atualmente, estão matriculados cerca de 840 alunos no Curso de Graduação, sendo uma metade no curso da manhã e a outra no curso da noite.

No Curso de Mestrado ${ }^{4}$ estavam inscritos em dezembro de 1992: 47 alunos, somente cursando disciplinas; 33, somente elaborando dissertação; 3 , com dissertação apresentada, aguardando oportunidade de defesa; 2, com matrícula trancada. Dos alunos que abandonaram o Curso, 3 completaram os créditos e 21 , não.

4.4 - Participação na administração

Acontece através da representação discente nos órgãos deliberativos da Faculdade, com direito a voz e voto, de maneira formal. Informalmente, os alunos têm livre trânsito junto às chefias e Direção. Junta- 
mente com professores e funcionários, elegem a direção da Casa.

4.5 - Presentação e representação

Acontece através do Centro Acadêmico André da Rocha e outras entidades estudantis.

4.6 - Assistência judiciária

É prestada à clientela carente, através do Serviço de Assistência Judiciária Gratuita SAJU.

\section{0 - Corpo docente}

\section{1 - Os primeiros professores}

Foram James F. Darcy (Filosofia do Direito) Manoel Pacheco Prates (Direito Romano) e Plínio de Castro Casado (Direito Público e Constitucional). Este último nominado foi o primeiro professor a ministrar a aula inaugural, no dia 04 de maio, dia seguinte à instalação da Faculdade, em sala da Inspetoria Geral da Instrução Pública.

\section{2 - Os atuais professores ${ }^{5}$}

As informações referem-se principalmente a julho de 1992. Contava a Faculdade com um corpo docente ao redor de 80 professores, incluídos os que laboram no Curso de Mestrado. Alguns professores estão afastados para servirem em outras Entidades (v.g. Universidade de Brasília) ou para freqüentar cursos de Pós-Graduação, no país ou no exterior.

\section{3 - Distribuição funcional}

Sua distribuição funcional é: 9 titulares; 21 adjuntos; 10 assistentes; 27 auxiliares de ensino e, ainda, 7 professores temporários ou substitutos. O Curso de mestrado conta com a colaboração de professores visitantes.

\section{4 - Titulação acadêmica}

Quanto à titulação, a Faculdade conta com 8 doutores, sete por Defesa de Tese e um por curso regular, havendo um professor com duas titulações; 11 mestres, 9 especializados e 39 graduados. Quanto aos pósgraduados, a maioria milita apenas no curso de graduação, vez que inexiste um canal administrativo de ascensão profissional e nunca foi aberto concurso para admissão de professores especialmente para os que o Dr. Macedônia acabou destinando ao pagamento de despesas da Faculdade.

Poucos sabem, mas Porto Alegre já teve um velódromo, uma União Velocipédica que patrocinava competições velocipédicas, ou seja, de bicicletas e triciclos. Estava situado logo abaixo da Faculdade de Engenharia, na rua da Várzea, atual Av. João Pessoa. Várzea esta que ainda existe e se chama Parque Farroupilha, também objeto de doação de particular. A União Velocipédica ali estava por concessão municipal, já que a várzea era próprio da Prefeitura.

$\mathrm{O}$ incansável Dr. Macedônia, que também era consultor jurídico da Prefeitura, conseguiu a doação da área desde que fosse indenizada a União Velocipédica. Professores, autoridades e acadêmicos uniram esforços para a obtenção do numerário, oito contos de réis, através de quermesse realizada em outubro de 1907, pelos acadêmicos de direito e moças da sociedade.

Para a construção, a Faculdade já vinha juntando dinheiro. Em 1907 já tinha depósitos de 52 contos de réis no Banco da Província. Os professores colaboraram abrindo mão de parte dos seus salários. O Governo do Estado doou 20 contos e Intendência, mais 5 contos. A Congregação autoriza o levantamento de um empréstimo de 70 contos. Mas, o custo da obra fo orçado em 312:530\$190.

\section{3 - A área}

O terreno foi obtido em duas etapas, entre 1907 e 1909, com área total de 7.039 $\mathrm{m}^{2}$, diminuído pelo recuo do muro frente à Av. João Pessoa, em razão do Viaduto Imperatriz Leopoldina.

\section{4 - A planta}

A planta foi apresentada pelo acadêmico Francisco Rodolpho Simch, na sessão da Congregação de 15 de junho de 1907. Aprovada, com a condição de que seu custo não excedesse os duzentos contos de réis.

O prédio é uma réplica do "Palais du Rhin", palácio de verão do Kaiser Guilherme II, imperador da Alemanha, como todos sabem, construído em Estrasburgo, capital da Alsácia, então território germânico, por conseqüência da guerra franco-prussiana, de 1870, onde a França foi derrotada. Este território foi reintegrado à França em razão da 1 a Grande Guerra, em 1919.

6.5 - A construção

Iniciou-se em 13 de junho de 1908 e foi terminada dois anos após. Foi entregue à Faculdade em 15 de julho de 1910 , sendo inaugurada no dia seguinte. Sofreu reformas e melhoramentos. Era menor. Em 1951, amplia-se para receber o atual Salão Nobre e maior área para a biblioteca. Em 1954, reforma-se a parte térrea para abrigar o atual Centro Acadêmico, o bar e o Saju. Novas reformas vêm sendo feitas, como maior espaço para o bar. Todavia, o edifício está pequeno e não acompanha o crescimento da Faculdade, quer em número de alunos, quer em novas atividades e/ou em novos cursos.

6.6 - Necessidade de maiores instalações

As turmas estão grandes demais. Não raro, duas turmas de alunos ocupam ao mesmo tempo uma mesma sala. O nosso Mestrado acomoda-se em instalações acanhadas, tanto para alunos quanto para professores e funcionários. Não existem salas de pesquisa e/ou orientação de alunos. Os professores não têm gabinetes de trabalho, mesmo aqueles poucos, com dedicação exclusiva.

A necessidade de estar próxima dos Foros e Tribunais do Estado em razão dos estágios profissionais inviabilizam a Faculdade de mudar-se para o Campus do Vale. A solução tem de ser encontrada dentro do Campus Central, ou com a construção de anexo ou com a cessão total ou parcial de prédios pertencentes a Faculdades e/ou Cursos que estão indo para o Campus do Vale.

A construção de anexos parece ao autor inconveniente ou contraproducente, devido à inexistência de terrenos vazios. Qualquer construção nova comprime a clientela dos Cursos em espaços ínfimos, sem contar o "amontoamento dos prédios", que ferem a estética e o meio ambiente.

A solução mais racional e menos dispendiosa, s.m.j., consiste em uma negociação 
envolvendo a Reitoria, a Faculdade de Direito e a Faculdade de Engenharia, que já tem parte instalada no Campus do Vale, tendo em vista o prédio do antigo "Parobé". As resistências são muitas, mas a boa vontade de todos não faltará. O "Parobé" está ao lado, o pátio é contínuo, o prédio foi recentemente reformado e tem estilo contemporâneo ao da nossa Faculdade, podendo ambas as casas constituir um conjunto harmonioso e funcional. Nele, além de mais salas de aula, poder-se-iam instalar condignamente todos os cursos de Pós-Graduação que a Faculdade vier a oferecer. Também as bibliotecas, a da Faculdade e a das Nações Unidas, poderiam receber instalações adequadas.

É um sonho plenamente realizável, sem prejuízo da Faculdade de Engenharia, de vez que a Faculdade de Economia está desocupando um prédio praticamente encartado naqueles ocupados pelos "engenheiros", por ter nova sede.

\section{0 - As bibliotecas}

7.1 - O início

A biblioteca, cérebro, memória e coração de qualquer instituição cultural, começou sem recursos de espécie alguma. Os pioneiros fizeram, conforme o dito popular, "das tripas coração", angariando livros de quem os possuía. E como isto era insuficiente, os livros eram comprados com os honorários profissionais dos próprios fundadores, como foi o caso do Des. James de Oliveira Franco e Souza, que a eles renunciou em favor da biblioteca. Em 1905, havia tão só 774 obras, aí incluídas as revistas.

7.2 - Duas bibliotecas ${ }^{6}$

Com a organização da Universidade, que reune as obras em uma biblioteca central, aquelas das faculdades restringem-se, cada vez mais, às obras específicas. Mas em nosso prédio, além da específica, temos a biblioteca da ONU.

\section{3 - Acervo}

Entre livros e documentos oficiais, em ambas as bibliotecas contam-se 72.460 obras, mais 728 publicações periódicas, em 12
1992, além de 2944 folhetos que versam os mais variados assuntos.

7.4 - Obras raras e preciosas

Registram-se 564 volumes, entre os quais toda a legislação portuguesa referente ao Brasil, no período de 1750 a 1822 .

7.5 - Usuários e consulentes

Usuários habituais, inscritos, são 1.852 Mas, entre consultas e empréstimos de livros, contaram-se no ano letivo passado 62.794 leitores.

7.6 - Professores escritores

A gestão do ministro da Educação Rubens Ludwig, que solucionou favoravelmente uma greve dos professores, trouxe dois inconvenientes. $\mathrm{O}$ primeiro foi a efetivação de professores sem concurso. $\mathrm{O}$ outro, foi terminar com o incentivo à produção científica, que consistia em uma gratificação de $20 \%$ sobre o salário do professor por um período de 5 anos após publicado o trabalho.

$\mathrm{Na}$ nossa biblioteca estão catalogados to dos os livros e artigos publicados pelos professores da casa, fato que poucos sabem, pois não temos o hábito de ler os nossos colegas.

\section{0 - Principais reformas de ensino}

8.1 - Decreto $\mathrm{n}^{\circ}$ 19.851, de 11.04.1931, chamada reforma de Francisco Campos, que organizou o Estatuto das Universidades brasileiras, tendo por modelo a Universidade do Rio de Janeiro. Contempla na Faculdade de Direito dois cursos: o de bacharelado (em cinco anos) e o de Doutorado (em dois anos). Institui o Conselho Técnico-Ad ministrativo, com atribuições administrativas e didáticas, consagrando a Congregação como o órgão máximo da Faculdade.

8.2 - Decreto $\mathrm{n}^{\circ} 5.758$, de 28 de novembro de 1934. A Faculdade é incorporada à Universidade de Porto Alegre. De entidade privada passa a entidade pública estadual. O nosso prédio passa a abrigar a Reitoria, além da Escola Superior de Comércio.

8.3 - Lei no 1.254, de 04.12.1950. A Faculdade é federalizada como entidade integrante da Universidade do Rio Grande do Sul.
8.4 - Regimento Interno de 06.11.1963. Promove a reorganização didático-administrativa, que mereceu aprovação do Conselho Federal de Educação, reconhecendo a Faculdade como instituto de ensino superior, com autonomia didática, administrativa e disciplinar. Renova-se a tentativa de introduzir o Curso de Doutorado. Ratificase a criação do curso noturno, já em funcionamento desde 1959.

8.5 - Regimento Interno, de 11 de novembro de 1970. Extingue o cargo de catedrático, acabando com a vitaliciedade dos professores. Aparece a atual carreira do magistério, constituída de Titular (cargo isolado), adjunto, assistente e auxiliar de ensino, todas com ingresso mediante concurso público de provas e títulos. A Faculdade constitui-se de quatro departamentos: Ciências Penais, Direito Privado e Processual Civil, Direito Público e Filosofia do Direito, Direito Econômico e do Trabalho, mais o Serviço de Pesquisa e Preparo Profissional. Surge o Conselho Departamental, que substitui em quase tudo as atribuições da Congregação, tornando-a praticamente decorativa. Introduz a Comissão de Carreira. O Consetho Departamental, com funções de ordem administrativa, compõe-se de: Diretor, ViceDiretor, representantes dos professores, alunos e funcionários.

Os cursos de Pós-Graduação contemplam: Doutorado e Mestrado (stricto sensu), Especialização (lato sensu). Ainda, prevê cursos de aperfeiçoamento e extensão.

8.6 - Atual currículo ${ }^{7}$

E fruto da resolução $n^{\circ} 23 / 86$, da III Câmara do Conselho de Ensino e Pesquisa da UFRGS (COCEP) e vige desde 1987. Sua principal alteração, cuja adaptação ainda perdura, foi a separação dos cursos diurno $(160.0)$ e noturno (058.0), sendo este último cumprido em 12 semestres letivos, por força da redução da carga horária semestral. Tal medida dificulta, para não dizer impede, a transferência de alunos de um turno para o outro, criando na prática duas faculdades de Direito, públicas e gratuitas, que funcionam no mesmo prédio, impermeáveis.
8.7 - Créditos

Oferece créditos obrigatórios, obrigató rios-alternativos e opcionais, mais aqueles referentes à Prática Desportiva, perfazendo uma carga horária de 3.390 horas/aula. Torna facultativo o Estágio Profissionalizante, a ser ministrado no turno da tarde.

8.8 - Colaboração de outras unidades da UFRGS

A Faculdade recebe a colaboração de outra unidades da UFRGS, para cumprimento do seu currículo: Cooperativismo e Introdução à Economia Política (ECO), Prática Desportiva I e II (EFI), Filosofia Geral, Psicologia Geral, Cultura Brasileira, Estudos de Problemas Brasileiros I e II, Introdução à Sociologia do Direito (HUM), Língua Brasileira (LET).

8.8.1 - Colaboração com outras unidades da UFRGS

Por sua vez, a Faculdade colabora com o currículo de outras unidades, lecionando um total de 42 créditos, sob o nome genérico de Instituições de Direito, as quais podem ser interpretadas como sendo o "ensino do Direito para não-advogados", ou seja, pretende familiarizar o leigo com a Ciência do Direito, fornecendo-lhe subsídios para que ele possa discernir o momento profissional em que é necessária a colaboração de uma advogado. Como segue: Instituições de Direito Privado e Legislação Comercial (de Administração de Empresas Públicas, Idem, de Empresas Privadas), Instituições de Direito (de Ciências Econômicas, de Ciências Contábeis, de Ciências Atuariais, Bacharelado e Licenciatura em Filosofia, Biblioteconomia), Direito para Processamento de Dados (Fac. de Ciências da Computação), Direito Comercial (Fac. de Ciências Contábeis, de Ciências Atuariais), Legislação de Seguros (Fac. de Ciências Atuariais), Fundamentos de Direito e Legislação Esportiva (Ed. Física) e Legislação de Ensino (Fac. de Educação).

8.8.2 - Colaboração com outra Universidade

Por força de Convênio firmado entre a UFRGS e a UNOESC, de Joaçaba-SC, o 
Departamento de Direito Privado e Processo Civil cedeu um professor-doutor, em tempo parcial, para lecionar e colaborar em cursos a nível de Especialização, em Direito Civil, em Direito de Processo Civil e em Direito do Trabalho.

8.9 - Comissão de carreira e departamentos A organização e planejamento do Curso de Bacharelado é atribuída à Comissão de Carreira. A Faculdade se constitui através dos 4 departamentos, os quais integram Conselho Departamental.

8.9.1 - Direção da Faculdade

A estrutura administrativa e organização acadêmica é exercida por um diretor, um vice-diretor, assessorados pelo Conselho Departamental, que é mantido. A Congregação é mantida, mais por tradição que por atribuições, exaurida que foi pelos Departamentos.

8.9.2 - A escolha dos diretores

Por resolução do Conselho Departamental, a escolha do Diretor e Vice-Direto acontece através do voto direto, secreto, estamental, ponderado, dela participando funcionários, alunos e professores, à razão de um terço para cada categoria de eleitores, vedada a votação por mais de um estamento.

\section{0 - Corpo funcional}

9.1 - A participação dos funcionários:

Eles somam 36, nos mais diversas funções. Afora o desempenho de suas tarefas, como é óbvio, eles participam, como os estudantes, da administração da Faculdade, por meio de seus representantes nos órgãos colegiados e na escolha da direção. O relacionamento com os órgãos diretivos é de ordem pessoal e quase sempre informal.

\section{0 - Pós graduação}

10.1 - Curso de mestrado

Finalmente, saiu do plano das intenções para o das realidades. Estamos recém no mestrado e precisamos chegar ao doutorado, para não frustrar as expectativas dos filhos da terra. Verdade, em épocas anteriores, a Faculdade já proporcionou cursos de 14 especialização. Mas somente a partir da $\mathrm{Re}$ solução no 12/85, da Câmara Especial de Pós-Graduação e Pesquisa, houve o parecer favorável da Capes, em 18.05.88.

A administração do Curso está a cargo de uma Comissão Coordenadora, constituída pelos professores Almiro do Couto e Silva, Adroaldo Furtado Fabrício, Ruy Rosado de Aguiar Junior e Sérgio José Porto.

\subsection{1 - Corpo docente}

Constitui-se de 6 professores permanentes, 2 professores visitantes e 10 professores participantes. Seis pertencem aos quadros da Casa. Oito são brasileiros, sendo que dois são de São Paulo, três são latino-americanos, três são franceses, um é espanhol, um é português e um é alemão.

10.1.2 - Titulação

Profes'sores permanentes: 2 doutores, 4 mestres, 1 especialista. Professores visitantes: 2 doutores. Professores participantes: todos doutores.

10.2 - Dissertações aprovadas

Até o momento foram apresentadas 5 dissertações: Resolução do Contrato por Incumprimento do Devedor (Ruy Rosado de Aguiar Junior), Causalidade Alternativa e o Dano (Vasco Della Giustina), Embargos de Terceiros (Luiz Felipe Silveira Difini), Motivações Ideológicas da Sentença (Ruy Portanova), A Tutela Jurisdicional dos Intereses Difusos ou Coletivos (Suzana Barata de Lacerda)

10.3 - Convênios interuniversitários

Objetivam o intercâmbio de professores, técnicos; pesquisadores e estudantes entre as universidades conveniadas. Já existe convềnio com as universidades: Val-de-Marne, Paris XII (França), Westphaelische Wilhelms-Universitaet, Münster (Alemanha) e Universidad Nacional de Rosario (República Argentina).

10.4 - Acordos com entidades culturais

Para a promoção de eventos culturais, o Mestrado firmou acordos com a AJURIS Escola da Magistratura do Rio Grande do Sul e com a Fundação Escola Superior do Ministério Público do Rio Grande do Sul.
10.5 - Vagas para o ano letivo de 1994

Estão sendo oferecidas 25 vagas para 1994. Destas, 7 são preferenciais para professores da Casa, mas que podem ser aproveitadas por outros candidatos se não preenchidas pelos docentes.

Os candidatos são submetidos a prova escrita, versando sobre Direito Civil, Direito dos Negócios, Direito Público e Processo Civil. Ainda, há entrevista e exame do curriculum vitae.

10.6 - Duração

Dois anos para o recebimento do título de Especialização em Direito (34 créditos) e mais dois anos para defender a dissertação, conditio sine qua non para a obtenção de Título de Mestre em Direito. A freqüência é integral, podendo em casos especiais ser abonada a freqüência em aulas e atividades em $10 \%$.

10.7 - Outras informações

Tais como estrutura curricular, documentação, horário, titulação, proficiência em línguas, bolsas de estudo e linhas de pesquisa, podem ser obtidas diretamente na Secretaria do Curso.

\section{0 - A revista}

Ninguém desconhece a dificuldade de toda a ordem que surge no momento de se apresentar um produto cultural que não rende lucros. A Revista da Faculdade é tão necessária quanto a biblioteca. Se esta é o repositório do saber já objetivado, do pensamento pensado, a Revista é o momento anterior, do pensamento vivo, do pensamento pensante. Não basta saber e nem basta ensinar. E preciso divulgar extra-muros, através de textos escritos que podem ir além da Casa e representar uma colaboração duradoura à causa da Justiça e do Saber.

11.1 - O surgimento

$O$ ideal da Revista somente se concretizou após 49 anos de existência da Faculdade. Apareceu em 1949, com 286 páginas, na gestão do diretor Prof. José Salgado Martins, com trabalhos de professores da Casa O segundo número saiu em 1950, com 205 páginas. Em 1951, apareceu o terceiro número, publicado em três volumes e consti- tuiu os Anais do Congresso Jurídico Nacional, comemorativo do Cinqüentenário da Casa: $1^{\circ}$ vol., com 472 p.; $2^{\circ}$ vol, que vai da página 473 à 899 ; e o $3^{\circ}$ vol. que vai da página 900 à 1.108 . Saiu o $4^{\circ}$ número em 1958, com 154 páginas. O número cinco, com 167 páginas, veio a lume em 1971; o número 6 foi publicado em 1972, com 295 páginas; e o número sete saiu em 1974 . O número oito é este que está publicado agora.

\section{0 - Considerações finais}

De 1974 até este ano de 1993, a Revista entrou em hibernação, por causas as mais diversas, mas especialmente por falta de recursos. Com ou sem revista, a Faculdade de Direito cresceu. Mas não comunicou o suficiente, quedando-se silenciosa, calada a provinciana, mais recebendo que contribuindo para a divulgação da cultura jurídica nacional. Graças à colaboração da Livraria do Advogado e à coordenação do Prof. Lippert, a nossa águia está ressurgindo das cinzas do esquecimento. Oxalá tais esforços tenham continuidade e continuadores. A nossa cultura e a tradição da Casa merecem ir bem mais além do ano 2.000 .

\section{Notas}

1 Prof. fundador $\mathrm{e}$ diretor da Faculdade desde nov/1904 até mar $/ 1936$

2 Prof. Titular de Direito Civil, fundador e primeiro coordenador do curso de Mestrado, falecido em maio de 1992.

${ }^{3}$ Sociólogo, jurista e educador.

${ }^{4}$ Fonte: Secretaria do Mestrado.

5 Fonte: Secretaria da Faculdade.

${ }^{6}$ Fonte: SBU.

7 Fonte: Catálogo dos Cursos de Graduação - UFRGS, 1990 